comments on the cases, the candidate will sometimes (as I did) feel embarrassed that a vital clue has been overlooked; he can very seldom feel annoyed with the authors for witholding essentia information. These case discussions are almost invariably good, although sometimes a little carelessness is observed such as the frequent use of the phrase 'blood sugar' and the consistent incorrect spelling of the word 'pruritus'. The authors conclude their comments on each case either with a statement about what happened to the patient or with a brief discussion of the diagnosis and treatment of the condition described; the latter are sometimes a little weak.

This book is compulsive reading and will be found invaluable by all candidates for Part II MRCP(UK). Indeed, it can be very usefully used by more senior physicians as a means of self-assessment and continuing education, and by students as a diverting and stimulating supplement to more conventional texts. It is in no sense an exam crib and is more challenging and exciting than the familiar and rather turgid 'Aids to ...' type of book. Careful perusal of this text will be rewarding to all students of medicine -from undergraduate to consultant. The authors are to be congratulated on producing a book which offers excellent value for the price.

J. ANIDERSON,

Royal Victoria Infirmary. Newcastle-upon-Tyne NFI 4LP.

\section{Advances in Neurology Vol. 29. Neurofibromatosis (von Reckling- hausen Disease). (Genetics, Cell Biology and Biochemistry}

Edited by V. M. Riccardi and J. J. Mulvihill. Pp. xix +282 . illustrated. Raven Press, New York, 1982

There are available a number of books on relatively rare genetic disorders. Tuberose sclerosis, Huntington's disease and myotonic dystrophy have all been the subject of monographs. Neurofibromatosis has not been neglected. This is the commonest dominantly inherited disease, with a birth frequency of 1 in 3,000 and a load of about 200 fresh cases a year.

There have been 4 books written in English on the subject although the last, the excellent monograph by Crowe et al.. was published in 1956. Clearly, this subject needs to be updated. Recent interest in the 'elephant man' has led to adverse publicity about the severity of neurofibromatosis. To redress the balance and to inform doctors about the frequency of the disease, a lay society-the National Neurofibromatosis Foundation-was formed in the USA and the conference which culminated in this monograph was, in part. sponsored by the group. (A similar society, 'Link'. now exists in the United Kingdom).

The book is divided into 5 sections. The first deals with the clinical and pathological aspects of this disease, and includes an assessment of the frequency and extent of malignancy, and of the relationship between central and peripheral neurofibromatosis. Then follow sections covering current research on both nerve growth factor and on the biology of the neural crest cells. Neurofibromatosis (a neurocristopathy) is thought to be the result of a defect in the differentiation or migration of the neural crest cells because of an intrinsic genetic defect or a defect in the immediate environment. Nerve growth factor might be involved in the persistence of the normally transient neural crest. Whatever the final solution might be, these chapters constitute the most comprehensive and stimulating available account to date.

The clinical diagnosis is still a problem. Riccardi states 'I do not consider café-au-lait spots alone as sufficient for the certain diagnosis'-although three neurofibromas might be sufficient.

The volume ends with a profile of Von Recklinghausen and his pupils and includes a translation of the original case report. If this volume is placed alongside Crowe. Schull and Neel's 1956 mono- graph, all the known facts relating to neurofibromatosis will be a hand. The volume is highly recommended.

M. BARAITSER,

Hospital for Sick Children,

Great Ormond Street,

London WC1.

\section{A Colour Atlas of Surgical Pathology}

By W. Guthrie and R. Fawkes. Pp. 229, illustrated. Wolfể Medical Publications, London, 1982. £35.00.

The colour illustrations of macroscopical and microscopical aspectsof surgical pathological specimens in this book are of excellent quality showing artistic as well as scientific merit.

In general, the range is comprehensive and many condition encountered in a surgical pathology practice in this country are referred to. The authors profess two aims in the work, one of which is. admirably met. that is, of providing the practising histopathologisio and surgeon with a ready reference to illustrations of a wide range ob common or well-known disorders. The reviewer must admit to som reservation however, about the authors' assessment that this work is 'sufficient to satisfy the needs of undergraduate and postgraduate students preparing for examinations in pathology'. and it seem is proper to look at the book in the light of this claim and in particulaf in relation to the training of pathologists.

Illustrations are of course helpful as an introduction to a conditionand sometimes even for purposes of revision, but there is a seriousdanger that the student will consider pathological diagnosis as ap exercise of matching features observed in the theatre, the cryostad room or paraffin laboratory with pictures in a book and it is sugete agreed by most teachers that resemblance is really not a basisoo identification. If the authors of this book had taken advantage of remarkable opportunities presented by their very fine illustrakīn and indicated in the text the criteria on which assessments are based referring at the same time to differential diagnostic issues, thes postgraduate might have derived a greater benefit from tho individual pictures.

In addition, whereas it may be asking too much for an occasiona命 reference to processes (the business of General Pathology perhaps) it seems reasonable to request some indication of the incidence ob various changes in the condition outlined. The student ought to have an idea of, say, the incidence of splenic involvement in Hodgkin's disease. In some instances. a helpful commentary accompanies the pictures, but the captions are sometimes inadequate to the degree of being misleading. For example, the criteria on which gluten-sensitive enteropathy rests includes reduction in the epithelial cell height? which is not mentioned, orcein-positive ground-glass cells aro insufficient for a diagnosis of viral hepatitis and accounts o․ hepatoblastomas ought to have a remark about connective tissuej lesions. Fibrous replacement of muscularis in chronic peptic ulce should surely be underlined and the term myxosarcoma will cause $a$ reaction in some quarters. The choice of specimens must reflect $a$ personal view and different conditions will always be favoured by some and not others, but it seemed surprising that mesothelioma if not mentioned. Also, an illustration of a hepatocarcinoma withoue cirrhosis requires a remark that these tumours are far moren frequently associated with cirrhosis.

However, the work seems to show care and enthusiasm for an important aspect of pathology and it is possible that the suggestions made may be considered for later editions. These are intended to bew constructive and the tone of the review to be complimentary.

K. WEINBREN,

Royal Postgraduate Medical School, London W12 0HS 